\title{
Adenomyoepithelioma Located Over the Tibial Tuberosity
}

Kyung Taek Kim, $\mathrm{MD}^{1}$, Min Soo Kang, $\mathrm{MD}^{1}$, Dae Cheol Kim, $\mathrm{MD}^{2}$, Hyung Min Yoon, $\mathrm{MD}^{3}$, and Lih Wang, $\mathrm{MD}^{3}$ ${ }^{1}$ Department of Orthopaedic Surgery, Dong-Eui Medical Center, Busan; Departments of ${ }^{2}$ Pathology and ${ }^{3}$ Orthopaedic Surgery, Dong-A University College of Medicine, Busan, Korea

Adenomyoepithelioma is a rarely occurring tumor and its generation in the limbs is extremely rare. We report a case of an adenomyoepithelioma over the proximal tibial tuberosity that was treated without any complications after an excisional biopsy with a literature review.

Keywords: Knee, Tibial tuberosity, Adenomyoepithelioma

Adenomyoepithelioma is a diagnostic term that has been used to describe an uncommon tumor, mostly of the breast ${ }^{1,2}$. Although its definition and classification as a single type of tumor remain controversial, adenomyoepithelioma generally refers to a tumor characterized by proliferation of epithelial cells lining the glands. Albeit rare, there are a few reported cases of adenomyoepitheliomas of the salivary glands and lung ${ }^{3,4)}$. In contrast, it has been extremely difficult to encounter adenomyoepithelioma of subcutaneous tissue over musculoskeletal structures ${ }^{5,6)}$. Herein, we report a case of an adenomyoepithelioma over the proximal tibial tuberosity with a review of the literature.

\section{Case Report}

A 41-year-old Russian female visited our clinic with a chief complaint of tenderness over a lump on the right tibial tuberosity. It had been present for 20 years without pain or changes in

Received August 26, 2013; Revised October 9, 2013;

Accepted November 11, 2013

Correspondence to: Lih Wang, MD

Department of Orthopaedic Surgery, Dong-A Medical Center, 26

Daesingongwon-ro, Seo-gu, Busan 602-715, Korea

Tel: +82-51-240-2593, Fax: +82-51-254-6757

E-mail: libi33@dau.ac.kr

This is an Open Access article distributed under the terms of the Creative Commons Attribution Non-Commercial License (http://creativecommons.org/licenses/by-nc/3.0/) which permits unrestricted non-commercial use, distribution, and reproduction in any medium, provided the original work is properly cited. size and level of tenderness. In physical examination, an approximately $2 \times 2 \mathrm{~cm}$ soft, round-shaped mobile mass was detected. Severe tenderness was noted, but neither abnormal sensation nor decreased mobility was evident. Plain radiography revealed increased soft tissue density immediately below the right tibial tuberosity (Fig. 1). Ultrasonography showed a hypoechoic multinodular lesion in the subcutaneous fat layer (Fig. 2).

Under local anesthesia, a 4-cm longitudinal incision was made below the tibial tuberosity, through which a salmon-colored mass measuring $2 \times 2 \times 1 \mathrm{~cm}$ was noted in the subcutaneous fat layer (Fig.

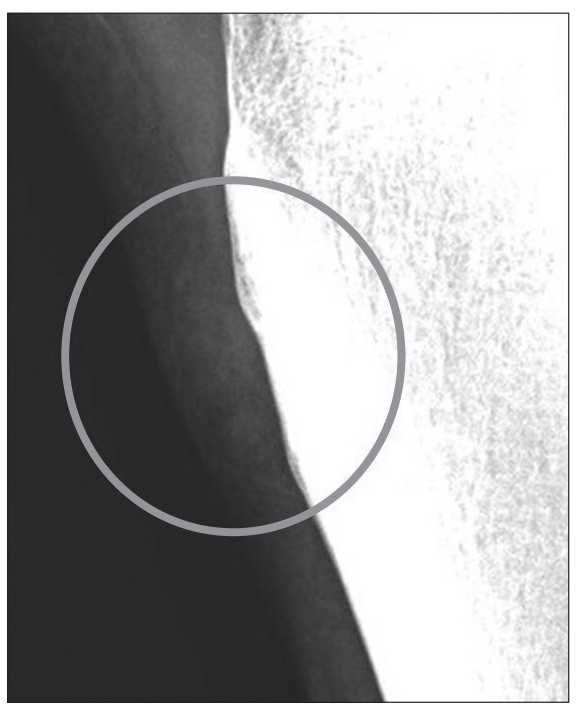

Fig. 1. Simple lateral X-ray showed increased soft tissue density. 
3) without adhesion to the adjacent tissue or bursitis. The mass was excised, taking care to minimize adjacent soft tissue damage. Histologic examination revealed the mass was composed of glandular structures lined by epithelial cells and surrounded by multiple layers of myoepithelial cells (Fig. 4). On immunohistochemical analysis, the inner epithelial cells was strongly positive for cytokeratin 7 (CK7) and the myoepithelial cells positively reacted to $\mathrm{p} 63$.

Postoperatively, neurological symptoms were not observed. The patient was satisfied with disappearance of tenderness after the excision of the tumor. At six months after surgery, there were no signs of complications and recurrence.

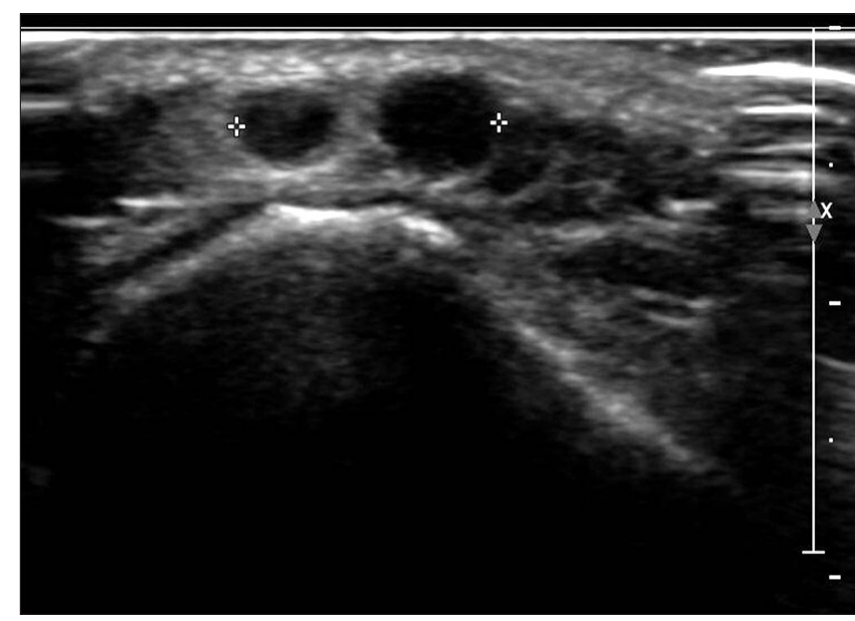

Fig. 2. Ultrasonography showed multiple hypoechoic nodular lesions in the subcutaneous fat layer.

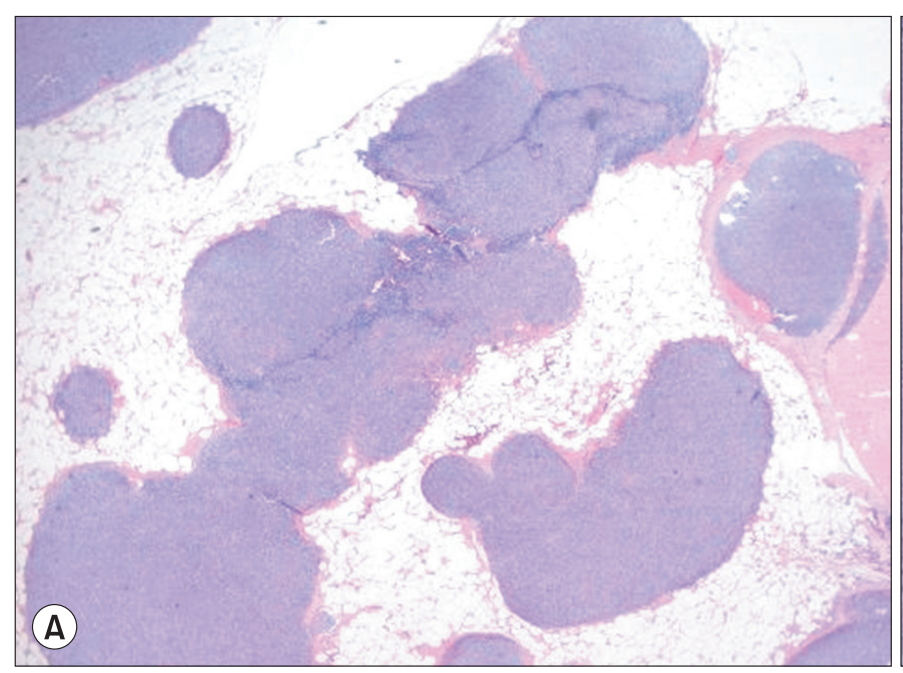

\section{Discussion}

Adenomyoepithelioma is a diagnostic term that has been applied to a broad range of rare tumors composed of epithelial and myoepithelial cells in the breast, salivary glands, and lung. Myoepithelial cells are present in apocrine and eccrine glands that produce and secrete sweat. Contraction of myoepithelial cells induced by mechanical, hormonal, and neurological stimuli contributes to expulsion of sweat from the gland and affects the size of holes in membranes of secretory cells and sweat production.

Few studies have addressed adenomyoepithelioma of the salivary glands and lung ${ }^{3,4}$, but reports on cutanoues/subcutaneous

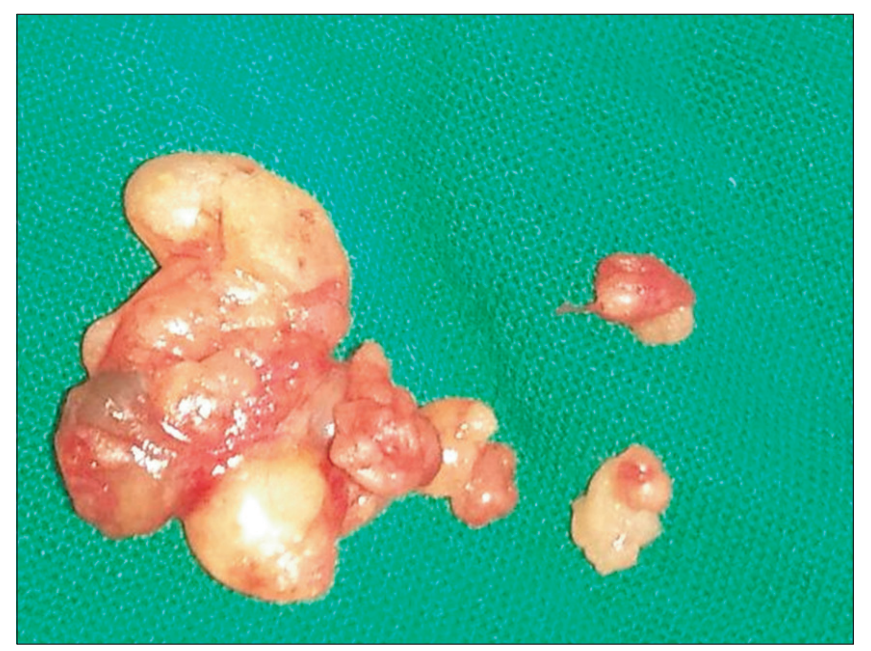

Fig. 3. Clinical photograph. A well-marginated soft mass was measured as 2 (proximal-distal length) $\times 2$ (medial-lateral length) $\times 1$ (anteriorposterior length) $\mathrm{cm}$.

Fig. 4. Low-power (A) histologic examination revealed a cystic lesion and multiple nodules $(\mathrm{H} \& \mathrm{E}, \times 20)$. Low-power $(\mathrm{B})(\mathrm{H} \& \mathrm{E}, \times 40)$ and mediumpower histologic examinations (C) revealed ductal luminal cells and myoepithelial cells (p63 staining, $\times 100)$. 
adenomyoepithelioma have been particularly rare ${ }^{5,6)}$. Adenomyoepithelioma of the skin and subcutaneous tissue share common characteristics with hidradenoma and adnexal tumors that exhibit myoepithelial differentiation, but the former can be distinguished by the following histopathological traits: 1) well-developed glands consisting of multiple layers of mature epithelial and myoepithelial cells, 2) dilated glands containing eosinophilic secretions, 3) the higher proportion of fibrous stroma than myxoid or hyalinized stroma, 4) absence of major components of other cutaneous/subcutaneous tumors, and 5) similarity with adenomyoepithelioma of the breast, salivary glands, and lung ${ }^{6}$. Thus, primary adenomyoepithelioma of the skin and subcutaneous tissue has been considered extremely rare and classified as one of the epithelial-myoepithelial tumors that include benign mixed tumors, myoepithelial tumors, parachordoma, and myoepithelial carcinoma ${ }^{7)}$.

A majority of epithelial carcinomas exhibit epithelial and myoepithelial differentiation and differential diagnosis includes a wide variety of tumors. Metastatic adenocarcinoma can be ruled out first based on clinical findings, imaging studies, and histopathological findings, and then adnexal tumors should be distinguished. Due to eccrine spiradenoma, the possibility of diagnosing as a rare variant of spiradenoma may be increased, but prominent myoepithelial cells and well-developed glands with dilated lumina help to avoid misdiagnosis. Primary subcutaneous myoepithelioma may be considered as a diagnosis because of the significant presence of myoepithelial cells. Although there is disagreement over whether myoepithelioma should be defined as a tumor that contains epithelial components, a majority of studies suggest that the most distinctive feature of the tumor is the sheets of myoepithelial cells without ductal epithelial components on histopathological images. Irrespective of its location in the breast, salivary glands, or skin, there is still no consensus on classification and labeling of the tumors consisting of both epithelial and myoepithelial cells ${ }^{8}$.

As above mentioned, with the definition of adenomyoepithelioma of the breast not clearly established, the term has been used to refer to a wide variety of tumors that are composed of epithelial and myoepithelial cells. The recent efforts to clarify the definition of adenomyoepithelioma of the breast have led to the following conclusions that can be also applied to subcutaneous lesions ${ }^{6}$. First, the term should be used to describe a tumor with a significant proportion of myoepithelial differentiation. Second, the term should not be used to refer to other types of epithelial-myoepithelial carcinomas, such as composite carcinoma. However, considering that cutaneous/subcutaneous adenomyoepithelioma has not been fully characterized and some studies have shown recurrence of the tumor located other than the skin after incomplete resection ${ }^{9)}$, it is advised not to restrict the use of the term to description of local lesions. Although there was no recurrence in our patient at six months after surgery, the risk for late recurrence should be closely followed.

In our case, additional examinations using imaging modalities, such as magnetic resonance imaging, were not performed under the assumption of a benign neoplasm, such as multiple epidermoid cysts, based on the preoperative clinical findings. Intraoperatively, the mass was found well demarcated and seemed benign to the naked eye, and thus excisional biopsy including the adjacent soft tissue was carried out. Immunohistochemical staining of the tumor was positive for p63 and CK7. p63 is a basal cell marker that is positive in adenocarcinoma, squamous cell carcinoma, urothelial carcinoma, and large cell carcinoma. CK7 is useful to determine cell differentiation stages in primary and metastatic carcinoma and CK7 positivity is suggestive of small cell carcinoma of the lung, breast cancer, and endometrial adenocarcinoma ${ }^{10)}$.

In contrast to the relative abundance of epithelial-myoepithelial carcinoma of the skin and subcutaneous tissue, there are only two reported cases of cutanoues/subcutaneous adenomyoepithelioma in the literature ${ }^{5,6}$. Although the two types of carcinomas exhibit the same histological features, their clinical and radiological manifestations are different. Therefore, we believe that further studies with accumulated cases are needed to provide a better understanding of cutanoues/subcutaneous adenomyoepithelioma.

\section{Conflict of Interest}

No potential conflict of interest relevant to this article was reported.

\section{References}

1. Tavassoli FA, Devilee P. Pathology and genetics: tumours of the breast and female genital organs. WHO Classification of Tumours series. Lyon, France: IARG Press; 2003.

2. Rosen PP. Adenomyoepithelioma of the breast. Hum Pathol. 1987;18:1232-7.

3. Raubenheimer EJ. The myoepithelial cell: embryology, function, and proliferative aspects. Crit Rev Clin Lab Sci. 1987;25:161-93.

4. Tsuji N, Tateishi R, Ishiguro S, Terao T, Higashiyama M. Adenomyoepithelioma of the lung. Am J Surg Pathol. 
1995;19:956-62.

5. Wallis NT, Banerjee SS, Eyden BP, Armstrong GR. Adenomyoepithelioma of the skin: a case report with immunohistochemical and ultrastructural observations. Histopathology. 1997;31:374-7.

6. Saadat P, De Clerck BK, Vadmal MS. Primary cutaneous adenomyoepithelioma. Ann Clin Lab Sci. 2012;42:287-92.

7. Mentzel T, Requena L, Kaddu S, Soares de Aleida LM, Sangueza OP, Kutzner H. Cutaneous myoepithelial neoplasms: clinicopathologic and immunohistochemical study of 20 cases suggesting a continuous spectrum ranging from benign mixed tumor of the skin to cutaneous myoepithelioma and myoepithelial carcinoma. J Cutan Pathol. 2003;30:294302.

8. Kiaer H, Nielsen B, Paulsen S, Sorensen IM, Dyreborg U, Blichert-Toft M. Adenomyoepithelial adenosis and lowgrade malignant adenomyoepithelioma of the breast. Virchows Arch A Pathol Anat Histopathol. 1984;405:55-67.

9. Loose JH, Patchefsky AS, Hollander IJ, Lavin LS, Cooper HS, Katz SM. Adenomyoepithelioma of the breast: a spectrum of biologic behavior. Am J Surg Pathol. 1992;16:868-76.

10. Bahrami A, Truong LD, Ro JY. Undifferentiated tumor: true identity by immunohistochemistry. Arch Pathol Lab Med. 2008;132:326-48. 